\title{
Predicting tree preferences from visible tree characteristics
}

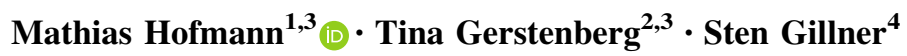

Received: 14 September 2016/Revised: 22 November 2016/ Accepted: 17 March 2017/Published online: 5 April 2017

(C) Springer-Verlag Berlin Heidelberg 2017

\begin{abstract}
This paper presents a psychological perspective to the selection of trees for urban residential areas. Sixty tree species suitable for urban planting sites were rated by lay participants regarding preference. We then used outward tree features to predict the preference ratings. Twenty-five different plant characteristics served as possible predictors in a regression model for tree preference. We found that the distinction between conifers and deciduous trees, the maximum tree height, and the crown height-to-width ratio were valuable predictors for preference, explaining more than $70 \%$ of the variance. This adds support for evolutionary theories of landscape preference. The regression model presented in this paper can be applied to calculate a preference estimate for other tree species using their known physical data, which may facilitate tree selection tasks in green space planning. By specifying preference-relevant tree characteristics, our findings may also inform the process of selecting diverse species for sites where a homogenous overall appearance is a planning goal.
\end{abstract}

Communicated by Aaron R. Weiskittel.

Electronic supplementary material The online version of this article (doi:10.1007/s10342-017-1042-7) contains supplementary material, which is available to authorized users.

Mathias Hofmann

mathias.hofmann@wsl.ch

1 Swiss Federal Institute for Forest, Snow and Landscape Research WSL, Zürcherstrasse 111, 8903 Birmensdorf, Switzerland

2 Forest Research Institute Baden-Württemberg, Wonnhaldestraße 4, 79100 Freiburg, Germany

3 Centre for Interdisciplinary Research in Technological Development (ZIT), TU Dresden, 01062 Dresden, Germany

4 Institute of Forest Botany and Forest Zoology, TU Dresden, Pienner Str. 7, 01737 Tharandt, Germany
Keywords Tree shapes - Urban planning · Nature perception $\cdot$ Street trees $\cdot$ Green spaces

\section{Introduction}

Urban nature plays an important role for the attractiveness of urban environments because it provides a large number of ecosystem services such as shading, cooling, clean air, and clean water (Gómez-Baggethun and Barton 2013). The benefits from urban nature to human health and psychological well-being have become a focal point of ecosystem service and psychological research (James et al. 2009). Also, the perceptions and preferences of the people living in or working in cities are increasingly becoming of more interest to both ecologists and urban planners (Berkowitz et al. 2003). Research has shown that people with more green spaces in their residential areas report better health (Maas et al. 2006). They not only feel healthier, there are also a number of objectively measurable health benefits like lower levels of stress hormones (Honold et al. 2015) or decreases in cardiovascular and lower respiratory diseases (Donovan et al. 2013). It has also been found that for people living in greener areas health inequalities related to income deprivation are less pronounced, suggesting that urban nature may be a means to reduce socioeconomic health inequalities (Mitchell and Popham 2008). Urban nature also produces psychological benefits, e.g., the ability to concentrate on strenuous tasks increases after exposure to nature (Berman et al. 2008; Hartig et al. 2003). Above that, urban nature increases neighborhood safety, with the number of reported crimes being lower in neighborhoods with more green (Kuo and Sullivan 2001). Overviews of these and other human benefits from nature are provided by 
a number of current reviews (Bowler et al. 2010; Haluza et al. 2014; Hartig et al. 2014; Keniger et al. 2013).

In the face of increasing urbanization (United Nations 2014) and expected climate change (IPCC 2014), the importance of urban nature for human quality of life will increase (Hägerhäll et al. 2010). It has become customary for cities to introduce policies for maintaining urban nature, among those are often specific regulations regarding the management of urban trees on both public and private ground (Conway and Urbani 2007). However, the impacts of urban vegetation on human life are manifold and they even include detrimental effects, so-called ecosystem disservices (Döhren and Haase 2015; Säumel et al. 2016). It is therefore important that urban nature meets human demands as closely as possible. In designing the urban vegetation of the future, i.e., when selecting tree species to be planted at urban sites, two tasks must be balanced: First, the species-site fit must be considered for the vegetation to thrive in the harsh urban conditions (Cekstere et al. 2008; Conway 2007; Gillner et al. 2014). Second, possible preferences by the residents for certain vegetation features should taken into account. Some research in this domain points toward possible trade-offs between esthetic evaluation and ecosystem services (Zheng et al. 2011). Concerning urban nature preferences, it is crucial to acknowledge differences between experts and laypeople: While the basic psychological processes for environmental perception are equal in both, there are cognitive differences in the processing of the perceived information. The greater knowledge of experts in regard to environmental design alters their perceptions and judgments (Johnson 1995; Rambow and Bromme 1995). For example, experts in landscape planning may show a preference for species-rich, natural urban areas because they are aware of biodiversity values. Laypeople, however, may reject these areas in favor of formal parks, possibly because they find those more orderly (Hofmann et al. 2012). This illustrates substantial expert-laypeople differences which necessitate more basic research into laypeople's environmental perception and preferences. Only if these differences are explored and made known to the experts, they may apply this knowledge in urban green space design. While knowledge exists about human benefits and preferences regarding urban nature in general (Hartig et al. 2014), there is a paucity of data regarding the issue whether specific tree species or certain tree characteristics have different impacts on tree preferences. In previous studies using schematic tree icons, wide crown shapes were preferred over conical or columnar forms (Sommer and Summit 1995, 1996; Summit and Sommer 1999). Using manipulated photographs of urban scenes, it was found that spreading trees were rated as more attractive than rounded or columnar trees (Lohr and Pearson-Mims 2006). As a common theme in these results, one may conclude that wider crowns are preferred to more narrow shapes. It may be argued that this is in accord with evolutionary theories for human environmental preferences like the savannah hypothesis (Orians 2001).

A classic theory regarding human visual perception is Gestalt theory (Wertheimer 1923; Koffka 1922) which makes a number of predictions regarding visual perception of certain shapes and their preferences [for an introduction, see Todorovic (2008)]. Among these, "Gestalt laws" is the closure principle which states that distinct elements tend to be grouped together in human perception if this forms a closed, complete figure. In general, Gestalt theory predicts that shapes which can be perceived more easily are preferred over difficult, complex shapes. The few existing studies relating tree characteristics to human preferences employed this Gestalt approach in that they used schematic versions of tree shapes as predictors for preference.

It may, however, be assumed that more tree characteristics than the overall shape of the crown are relevant to human tree perception and tree preferences. In contrast to studies using coarse tree shapes, each varying a limited number of tree characteristics, the present study was not rooted in a comparable selection and variation of tree characteristics. Rather we used a sample of real photographs of street tree species, featuring a natural variation in many different tree characteristics (see Table 2). To make the study applicable to urban design, the photographs were to be judged by volunteers in regard to preference in their residential area. Although we used more realistic stimuli than previous studies on tree preferences and did not deliberately manipulate the tree characteristics in the stimuli, we expected to replicate the major findings: We generally hypothesized that wide crowns would be preferred over more slender crowns, which would also be in accord with the savannah hypothesis (H1). We also hypothesized that dense crowns would be preferred over sparser crowns; this would correspond to the closure principle of the Gestalt theory, according to which clearly distinguishable shapes are preferred (H2). In particular, we expected lower preferences for coniferous trees than for deciduous trees because they combine features from both $\mathrm{H} 1$ and $\mathrm{H} 2$ : Crowns of coniferous trees are usually less wide and less voluminous and show less closure (H3). Regarding additional tree characteristics, we used an explorative approach and did not devise hypotheses.

\section{Materials and methods}

\section{Materials}

From an Internet database of urban woody species ("citree"; Vogt et al. 2017), we randomly selected 60 
native and non-native, commonly used tree species for urban sites in Central Europe (46 deciduous, 14 coniferous). To obtain suitable photographs, in a first step images of adult trees in full foliation during summertime were obtained using internet image search. The trees were to be depicted without any injuries, branch cuts or symptoms of damages or diseases. Pictures showing trees in stages of sprouting leaves, autumn leaves, as well as trees with fruits or blossoms were excluded to reduce additional complexity which might stem from temporal changes in tree appearance over the course of the year. In a second step, the pictures were judged by urban forestry experts to ensure that they depicted species-specific features showing typical characteristics in leaf color, leaf density, branching pattern, growth direction, and crown shape. In a third step, we ensured that the images were similar regarding the depicted background. We also paid attention to image quality, trying to keep constant physical image parameters which could have an impact on preference ratings (Tinio and Leder 2009), such as exposure, contrast, sharpness, or saturation. This judgment was made on a subjective basis and was limited by the images available at the time of the image search. Finally, we also removed humans or animals from some photographs using image editing software. The resulting 60 photographs showed an adult specimen of each species in the image center (see Fig. 1 for examples; the sources of all 60 images is found in Electronic Supplementary Material). The photographs were developed on 10 by $15 \mathrm{~cm}$ paper.

\section{Study participants}

The study participants $(n=225)$ were recruited from the general public via bulletins in public buildings and online advertisements. They participated voluntarily and received a monetary compensation. The mean age of the participants was 28 years (median 25, range 18-62, $\mathrm{SD}=8.7$; German mean age 44 years). Among the participants, $60 \%$ were female (German population 51\%), 49\% were married or in a stable relationship (German population 52\%), 7\% had children younger than 10 years [compared to $17 \%$ for the German adult population (people 18 years old and older)], and $22 \%$ used a private garden. In terms of their highest educational qualification, $54 \%$ of the participants had a higher education entrance qualification (Abitur) and 31\% had a university degree or equivalent [compared to 20 and $17 \%$, respectively, for the German population (people older than 15 years)]. In summary, compared to the German population, the sample was younger and better educated (all comparisons from the 2011 census; Zensusdatenbank 2013).

\section{Procedure}

The data were collected in a university room furnished only with chairs and tables in Dresden, Germany. After the participants had familiarized themselves with all of the images, they were asked how much they would like to have each tree in their living environment (within a $300 \mathrm{~m}$ radius around their home). For each tree, they indicated preference on a $10-\mathrm{cm}$ blank continuous scale (ends labeled as "very little" and "very much"). The scales were printed on sheets of paper and the participants labeled each scale with the number of each judged tree photograph. The participants were instructed to base their judgment only on the tree in the center of the picture, disregarding the contents of the background or the image quality. The trial took about 15 min per person. All data were collected anonymously.

\section{Data analysis}

We converted the preference markings into preference values ranging from 0 to 100 by measuring the distance (in $\mathrm{mm}$ ) from the left end of the scale. For each tree, we calculated a preference aggregate using its mean rating from all participants. We then conducted a multiple regression analysis to predict the measured preferences. The data for the possible predictors originated from the "citree"
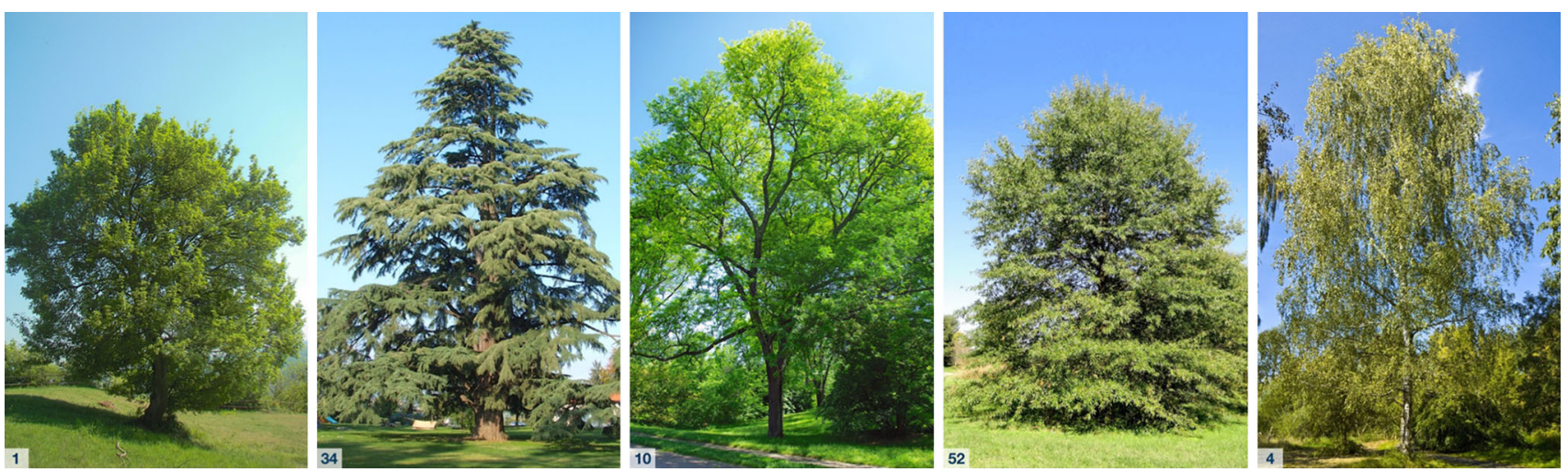

Fig. 1 Examples of the images used in the study (for image credits, see "Appendix 1") 
database of urban woody species (Vogt et al. 2017). The variables used as possible predictors are listed in Table 2. One additional predictor was derived from two database variables: We used the crown height-to-width ratio as a rough indicator for the basic crown appearance. It was calculated by dividing mean crown height by mean crown width, and it ranged from 0.76 to 6.04 .

Starting with a full model using all predictors, we employed a stepwise backwards variable selection procedure to exclude those variables with no predictive power, using the AIC (Akaike 1987) as a decision criterion. We tested for multicollinearity among the predictors by calculating the condition index (Belsley et al. 1980; Belsley 1991). This yielded a maximum condition index of 6.46 which is well below the problematic rule-of-thumb threshold of 30 (Belsley 1991), indicating that multicollinearity is not a major concern for the present data. To check the stability of the final model, we systematically excluded different combinations of the predictor variables (see Table 4).

To identify possible demographic effects, mixed effects models using the unaggregated preference data were constructed. One model contained the predictors from the final regression model as fixed effects and participant code and tree species as random effects (without interaction term). We inspected the residual plots and found no obvious deviations from either homoscedasticity or normality. For a second model, we additionally entered the following categorial demographic variables as predictors: gender, age group (median split), educational qualification, relationship status, parental status, and garden ownership. We then compared the two models using likelihood ratio tests.

We used $R$ for all data analyses (R Core Team 2015, version 3.2.0), with the lme package for mixed effects modeling (Bates et al. 2014, version 1.1-9) and the boot package for bootstrap resampling (Canty and Ripley 2015; Davison and Hinkley 1997, Version 1.3-16) to check the stability of the regression model.

\section{Results}

\section{Preference ratings}

The participants used the complete spectrum of the preference rating scale $(0-100)$, and the overall mean preference was 60.7 (median $=64, \mathrm{SD}=25.1$ ). Overall, ratings of more preferred trees varied less than the ratings of less preferred trees (see Fig. 2).

Upon closer inspection, it became apparent that the ratings and variances differed systematically by foliage: deciduous trees were significantly more preferred than coniferous trees, and their preference ratings varied less (see Table 1; Fig. 2, for preference ratings for each tree

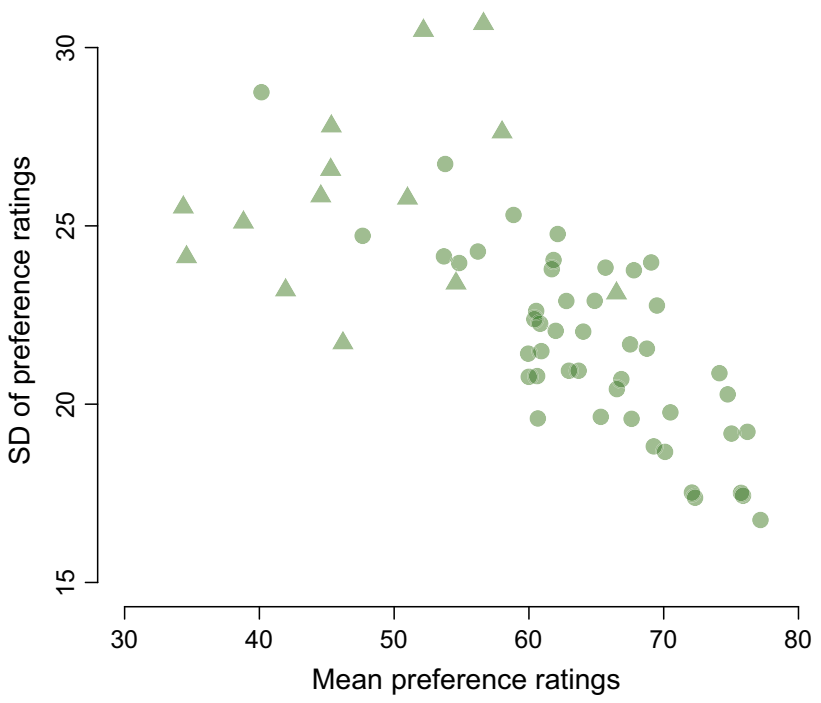

Fig. 2 Variance of observed tree preference ratings ( $N=60$ trees; of these: 14 coniferous trees $=$ triangles, 46 deciduous trees $=$ circles)

species, see "Appendix 2"). The variances of the deciduous trees preference ratings decreased with increasing preference, whereas the variances of the coniferous trees did not differ in relation to preference (see Fig. 2).

Some of the predictors were correlated with the preference ratings, notably foliage (deciduous vs. coniferous trees), crown diameter, and crown height-to-width ratio (calculated as: mean crown height divided by mean crown width) (see Table 2).

\section{Preference prediction}

Starting with a full model using all possible predictors, a stepwise backwards variable selection process resulted in a model with three predictors for preference: Foliage (deciduous vs. coniferous trees), height-to-width ratio of the crown (calculated as: mean crown height divided by mean crown width) and maximum tree height. Together, they explained over $70 \%$ of the preference variance $\left(R^{2}=.7257\right.$, adj. $\left.R^{2}=.7105, F(3,54)=47.63, p<.001\right)$. Ordinary nonparametric bootstrapping (using 1000 repetitions) yielded similar values for the determination coefficients: $R^{2}=.7570$ (bias $=.0021, \mathrm{SE}=.0691,95 \%$ CI .5563-.8523), adj. $R^{2}=.7336($ bias $=.0061, \mathrm{SE}=.0701,95 \%$ CI $.5494-$ .8373). Table 3 lists the regression coefficients and the intercorrelations of the predictors. Figure 3 shows a visualization of the final preference prediction model.

Checking the stability of the final model, we systematically excluded different combinations of the predictor variables. While the magnitudes of the predictors varied during this procedure, their signs remained stable (see Table 4), indicating an overall stability in the found relationship. 
Table 1 Tree preferences differ substantially between deciduous and coniferous trees $(* * * p<.001)$

Table 2 Tree characteristics and their correlations to preference ratings (Spearman's rank correlation coefficient)

\begin{tabular}{lllrr}
\hline & Deciduous trees & Coniferous trees & $t$ & $d f$ \\
\hline Preference, mean & 64.6 & 47.9 & $6.1933^{* * *}$ & 18.811 \\
Preference, median & 67.0 & 47.7 & $5.5398^{* * *}$ & 17.552 \\
Preference, SD & 21.7 & 25.7 & $-5.1060^{* * *}$ & 21.044 \\
\hline
\end{tabular}

\begin{tabular}{|c|c|}
\hline Tree characteristic & rho \\
\hline Foliage $($ deciduous trees $=1$, coniferous trees $=0$ ) & $.65^{* * *}$ \\
\hline \multicolumn{2}{|l|}{ Tree height (in $\mathrm{m}$ ) } \\
\hline Mean height & .09 \\
\hline Maximum height & .10 \\
\hline \multicolumn{2}{|l|}{ Crown diameter (in $\mathrm{m}$ ) } \\
\hline Minimum diameter & $.43 * * *$ \\
\hline Mean diameter & $.40 * *$ \\
\hline Maximum diameter & $.37 * *$ \\
\hline \multicolumn{2}{|l|}{ Crown height (in m) } \\
\hline Minimum height & .24 \\
\hline Mean height & .16 \\
\hline Maximum height & .10 \\
\hline Ratio of mean crown height to mean crown width & $-.35 * *$ \\
\hline \multicolumn{2}{|l|}{ Trunk length (from ground to first branching; in $\mathrm{m}$ ) } \\
\hline Minimum length & .15 \\
\hline Mean length & .08 \\
\hline Maximum length & .03 \\
\hline Tree originates from Europe ${ }^{a}$ & -.24 \\
\hline Tree provides a food source for bees ${ }^{a}$ & $.42 * * *$ \\
\hline Tree has ornamental flowers ${ }^{\mathrm{a}}$ & .14 \\
\hline Tree has ornamental fruit ${ }^{\mathrm{a}}$ & -.13 \\
\hline Tree may annoyingly drop fruit ${ }^{\mathrm{a}}$ & .23 \\
\hline Tree may emit unpleasant odors ${ }^{\mathrm{a}}$ & .10 \\
\hline Thorns or spikes present ${ }^{\mathrm{a}}$ & -.09 \\
\hline Tree emits noticeable fragrance ${ }^{a}$ & .23 \\
\hline Multi-stemmed tree ${ }^{a}$ & .15 \\
\hline Edibility $^{\mathrm{a}}$ & .03 \\
\hline Leaf area index (proxy for crown density; Bréda 2003; Chen et al. 1997) ${ }^{\mathrm{b}}$ & .03 \\
\hline
\end{tabular}

\section{No demographic differences}

Replicating the linear regression model using an analogous mixed effects model yielded estimates for the fixed effects which were very similar to the predictor weights in the regression model. A second mixed effects model contained demographic variables (gender, age, educational qualification, relationship status, parental status, garden ownership) as additional fixed effects. A comparison of these two models returned no significant difference, $\chi^{2}(11)=10.456, p=.4899$. This indicates that adding demographic variables to the regression model does not yield additional predictive precision.

\section{Discussion}

If urban green space planning is to orientate itself to human demands, it must be cognizant of human preferences for different kinds of urban nature in general, and for different 
Table 3 Using outward tree features to predict tree preference: together, foliage, maximum tree height, and height-to-width ratio of the crown explained more than $70 \%$ of the variance in tree preference $\left(R^{2}=.7257\right.$, adj. $\left.R^{2}=.7105, F(3,54)=47.63, p<.001\right)$

\begin{tabular}{|c|c|c|c|c|c|c|}
\hline \multirow[t]{2}{*}{ Predictors } & \multicolumn{2}{|c|}{ Unstandardized coefficients } & \multirow{2}{*}{$\begin{array}{l}\text { Standardized coefficients } \\
\beta\end{array}$} & \multirow[t]{2}{*}{$t$} & \multicolumn{2}{|c|}{ Correlations } \\
\hline & $B$ & SE & & & Foliage & Max. height \\
\hline (Intercept) & 64.24 & 2.50 & & $25.66^{* * *}$ & & \\
\hline Foliage: deciduous & 25.32 & 2.74 & 10.74 & $9.24 * * *$ & & \\
\hline Maximum height (in m) & 0.46 & 0.09 & 5.51 & $5.34 * * *$ & $-.41 * *$ & \\
\hline Crown $\mathrm{H} / \mathrm{W}$ ratio & -2.72 & 1.22 & -2.41 & $-2.23 *$ & $-.53 * *$ & $.30 *$ \\
\hline
\end{tabular}

Regression analysis results are presented in the first four data columns, intercorrelations of the predictors (Spearman's rank correlation coefficients) in the last two columns (for correlations of the predictors with preference, see Table 2)

Foliage coding: deciduous trees $=1$, coniferous trees $=0$

Crown $\mathrm{H} / \mathrm{W}$ ratio: crown height-to-width ratio (mean crown height $\div$ mean crown width)

$* p<.05 ; * * p<.01 ; * * * p<.001$

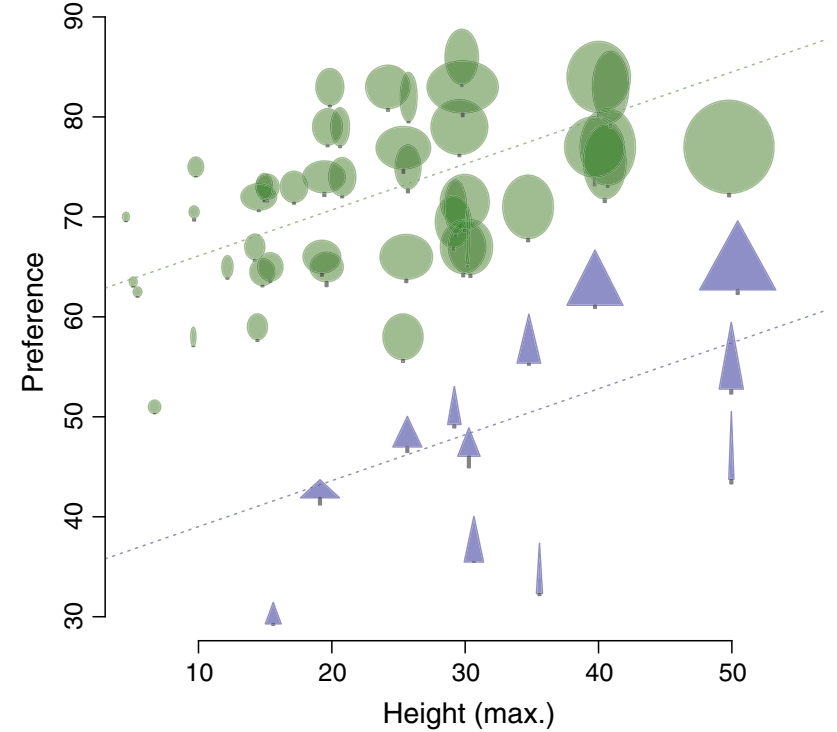

Fig. 3 Observed tree preference ratings as a function of maximum tree height. The regression lines (dotted) refer to the corresponding regression function of the preference prediction model (see Table 3), separated by foliage (coniferous vs. deciduous trees; triangular and round symbols, respectively). Crown height, crown width, and trunk length of the tree shapes in this figure correspond to real values (triangular shapes $=$ coniferous trees; circular shapes $=$ deciduous trees)

tree species in particular. The present study contributes to the knowledge of human tree preferences in taking a nonspecies-specific approach: It investigated how tree preference is influenced by certain tree characteristics which are each shared by different subsets of all tree species. In a previous study using computer-generated stimuli (Gerstenberg and Hofmann 2016), we had identified certain tree characteristics to be decisive in human perception: (1) the distinction between conifers and deciduous trees, (2) crown shape (oval vs. globular), (3) ratio of crown size to trunk height, and (4) the crown density. These features were used by the participants to distinguish among different trees. In this previous study, we had also found that crown size and density predicted preference in deciduous trees. In the present paper, we present a study which used more realistic stimuli and extended the preference prediction to confinerous trees.

\section{Tall, wide, deciduous trees are most preferred}

The results clearly show a dependence of tree preference on outward tree characteristics. Overall, there were significantly higher preferences for deciduous trees than for coniferous trees. In addition to these foliage-related differences, the maximum tree height and the crown heightto-width ratio are significant predictors of tree preferences. The demographic characteristics examined in this study had no additional value for preference prediction, hinting at the found relations to be rather general. There were also no differences in preference between native and non-native trees. To illustrate this, among the most preferred trees was Tilia cordata which is a native species, very common to European cities (Radoglou et al. 2009; Thomsen et al. 2016). Also among the most preferred species was Gleditsia triacanthos, a species which is native to North America (Burns and Honkala 1990) and only very seldom found in Germany.

The results provide support for the main hypothesis (H1), according to which wide crowns should be preferred over more slender crowns. The data do not support the second hypothesis $(\mathrm{H} 2)$ which predicted an effect of crown density on preference. The substantial difference in preference between coniferous and deciduous trees, however, supports our third hypothesis (H3). 
Table 4 Testing prediction model stability: multiple partial models were generated using different combinations of the predictors to compare magnitudes and the signs of the predictors. While the magnitude of the coefficients varied, their signs remained constant among all models, hinting at stable relationships

\begin{tabular}{lllll}
\hline Predictor combinations & \multicolumn{2}{l}{ Standardized regression coefficients } & \multirow{2}{*}{$R^{2}$} \\
\cline { 2 - 5 } & $F$ & $H$ & $C$ & $0.73^{* * *}$ \\
\hline$F, H, C$ (full model) & 10.74 & 5.51 & -2.41 & $0.70^{* * *}$ \\
$F, H$ & 11.93 & 5.29 & - & $0.57^{* * *}$ \\
$F, C$ & 8.77 & - & -1.82 & $0.28^{* * *}$ \\
$H, C$ & - & 2.50 & -7.24 & $0.56^{* * *}$ \\
$F$ & 9.74 & - & - & 0.00 \\
$H$ & - & 0.36 & - & $0.25^{* * *}$ \\
$C$ & - & - & -6.50 & \\
\hline
\end{tabular}

Predictor abbreviations: $F$ foliage, $H$ maximum height (in m), $C$ crown $\mathrm{H} / \mathrm{W}$ ratio

Foliage coding: deciduous trees $=1$, coniferous trees $=0$

Crown $\mathrm{H} / \mathrm{W}$ ratio: crown height-to-width ratio (mean crown height $\div$ mean crown width)

$* * * p<.001$
Our findings are in accordance with evolutionary theories of esthetic preferences, such as the savannah hypothesis (Orians 2001) which predicts that wide, spreading crowns are preferred because they indicate fertile habitats, providing advantageous living conditions for Homo sapiens. Preferences for savannah-like scenes have been reported in previous studies using photographs of forests (Balling and Falk 1982; Falk and Balling 2009). The present results show this relation to also be valid in an urban context because our subjects rated tree preference for their urban living environments.

Crowns of many deciduous trees form a large network of branches and twigs on multiple ramification levels. Crowns of many coniferous trees, however, exhibit more of a zig-zag shape consisting of large branches with fewer, comparatively shorter twigs. This way, crowns of deciduous trees are more visually coherent because they form one single shape. In this regard, our findings of deciduous trees being clearly preferred are consistent with Gestalt theory (Koffka 1922; Todorovic 2008), specifically its closure principle, according to which human vision prefers closed, complete forms over seemingly incomplete shapes. This argument points toward a contradiction in the evaluation of H2 (which predicted an effect of crown density on preference) and $\mathrm{H} 3$ (which predicted lower preferences for coniferous trees not only due to narrower crowns but also due to their crowns showing less closure). It is unlikely that the indictor for crown density used in this study (the leaf area index) corresponds to the argument regarding crown density made here (see also the remarks in the next paragraph) which would allow explaining the lacking support for $\mathrm{H} 2$ with lacking data. Hence, it may be concluded that $\mathrm{H} 3$ receives support from the data in this study only in terms of the hypothesis' argument relating to crown shape, not via the crown density argument.

\section{Validity of crown density indicators}

Considering the Gestalt principle of closure, one would expect more dense crowns to be preferred because they should more readily be perceived as closed shapes. This was not found in the present study, which may be due to a methodological issue of how the variable was operationalized: As an indicator for crown density, we used categorial estimates for the leaf area index of each species. This operationalization might have been too coarse.

Above that, this value might also have been invalid: The leaf area index describes the combined leaf area of a tree in relation to the ground area of its canopy (Bréda 2003; Chen et al. 1997). This may represent an indicator for crown density in terms of its vertical permeability, particularly for rain, but not for visual permeability from the angle the photographs were taken. In a previous study (Gerstenberg and Hofmann 2016), we had found preference to be predicted by crown density when it was operationalized as the ratio of pixels depicting parts of the crown to the number of pixels showing the background or the sky. In the present study, this was not feasible because the crown background was not homogenous enough for these analyses. Besides, the present study aimed at predicting tree preferences using typical values from species databases instead of values measured at images of single specimen.

\section{Strong preference prediction despite possible data inaccuracies}

Previous studies on the relation between tree characteristics and human preferences (Lohr and Pearson-Mims 2006; Sommer and Summit 1995, 1996; Sommer 1997; Summit and Sommer 1999) used coarse distinctions of tree appearance such as height, generic tree forms, or crown-to- 
trunk ratio. Also, they compared qualitative or ordinal categories and used rather artificial stimuli, such as drawings. Using this kind of stimuli, the distinctions to be studied could be manipulated very precisely. In the present study, we used photographs of different tree species which varied in regard to these parameters, and others. Where possible, we used continuous measures for a multitude of predictor variables and found linear relationships to preference.

Each photograph in the study depicted a single individual for each tree species. Although photographs were carefully selected to avoid unusual specimens, it is impossible to represent the entire spectrum of any species' leaf density, branching pattern, growth direction, and crown shape because they depend on the specific climatic and soil factors, environmental conditions, competition, and provenance (Ginau et al. 2013; Sæbø et al. 2005). Another critical point is that the photographs used in the study depicted trees in single stand without remarkable competition from other vegetation. That generally leads to lower heights, above-average crown height in relation to stem length, as well as to more regular crown shapes (Fraver et al. 2013; Jucker et al. 2014). This is crucial because the data for the predictor variables stemmed from a database which contains averages, and sometimes only rough estimates for the tree characteristics. Despite the inaccuracies that may be expected from such an approach, we found a good model fit. This indicates that the found relationships may be rather robust.

\section{Representativeness of the participants}

The subjects were younger and better educated than the German population, which may be judged as a weak point of this study. However, it may be argued that in these respects the general German population itself differs from city residents, for which the participant sample should be representative (but no comparison data were available). A number of factors contribute to an urban/rural disparity in Germany: Inhabitants of rural areas often have to move large to cities for higher education and employment. Moves as these are more relevant for younger people, resulting in the rural population being older (Euostat 2013) and exhibiting a smaller share of inhabitants with higher education (Autorengruppe Bildungsberichterstattung 2014; Statistisches Bundesamt 2015). Also, due to a more traditional understanding of social norms in rural areas, fewer adults have a history of higher education in rural areas than in cities, and still today, the likelihood for children to be sent to higher schools is lower in rural areas. In light of these arguments, it may be assumed that German city residents should be younger and better educated than the
German average and hence be more similar to this study's participants than the general German population would be.

\section{Limitations and consequences for future research}

Although we used realistic stimuli, evaluating photographs is a different matter than judging real-life trees in an actual setting, e.g., an urban neighborhood. An extensive metaanalysis (Stamps 2010), however, showed that color images were equivalent to onsite evaluations. Nonetheless, the photographs used in the present study did not depict trees in the residential area of the participants; instead, they depicted trees against a neutral background. Future research may hence opt for photographs of participants' actual residential areas and manipulate the images to feature different tree species. This approach would be more time-consuming and more labor intensive, but it could increase the external validity of the research because the study participants would likely be able to better relate to the presented, more familiar, images than to more general images. This means that for residential areas similar to the chosen area the study results would be more applicable than in the more general setup used in the present study. At the same time, this would, however, decrease generalizability, meaning that results obtained from such an approach would be less applicable for all residential areas in general.

To decrease research design complexity, the images depicted leaved adult trees only. However, for many urban planning tasks the preferences regarding younger trees may be more interesting because usually young trees are used for new plantings. For future research, it may thus also be of interest if and how preferences and evaluation criteria for younger trees differ from adult specimens.

There were also neither variations in leafiness and leaf color of the deciduous trees nor any visible sprouts, blossoms and fruit, and thereby no apparent seasonal effects. These may be a subject for further research, where a number of the variables which appeared to be irrelevant in this study (e.g., food source for bees, ornamental flowers, ornamental fruit, dropping fruit, noticeable fragrance, edibility) may show more predictive power.

\section{Applications for landscape planning}

The present results may be applied in urban planning, specifically in the process of tree selection. There may also be less obvious applications: In striving to achieve a homogenous overall appearance of a certain street or neighborhood, the same trees are often planted on the whole street or throughout the whole area, considerably limiting tree species diversity. For example, in a recent 
study, it was found that only six species make up almost $50 \%$ of the tree stock of the studied Danish municipalities (Thomsen et al. 2016). The resulting lack in tree species diversity may have serious consequences as it leaves the area vulnerable to climatic changes or new pests. A prudent approach to urban vegetation planning may incorporate the use of different species. The results of the present study may guide the selection process by offering criteria which can be used to select tree species being similar to one another regarding preference-relevant features.

Tree size may be an important issue in urban planning. Although large trees have been shown to be preferred in studies around the world (Camacho-Cervantes et al. 2014; Gundersen and Frivold 2008; Jo and Ahn 2012), they have certain disadvantages: For most tree species, it takes a long time until they reach their adult size. Also, when they are placed directly in front of a building, they hinder light from entering the rooms inside the building. Large trees will also be more often in conflict with construction plans than smaller trees and can cause serious damage to humans and infrastructure. However, there are also a number of advantages that larger trees provide above smaller trees: larger trees provide more cooling resulting from more shading and transpiration. While in colder, less sunny regions this may be considered a nuisance (Schroeder et al. 2006), cooling from trees can be a large asset for cities with warm, sunny summers (Gillner et al. 2015). There, this will be beneficial to human health and may even reduce energy needed for air conditioning. The study showed clear preferences for large, deciduous trees with wide crowns. Considering the low speed of tree growth, this may be interpreted as a plea against cutting down old trees on construction sites. It rather seems advisable to keep these trees and incorporate them into the design of the area or the new building. The preference for large trees may also be considered as an argument in questioning the general trend toward planting rather small trees in many cities.

\section{Conclusions}

The present study found that variations in preference between tree species can be predicted by objectively measurable tree features. Coniferous trees were notably less popular, but tree size and crown width were positively related to preference. While the version of the preference prediction model we propose in this paper may already enable users to determine preference estimates for different species, we believe that further refinements of the model may prove worthwhile, particularly regarding the relationship between crown density and preference. Our research may also inform city planning where it aims at achieving ensembles of street trees which are both species rich and appearing homogenous to laypeople in terms of the tree features relevant for preference.

Acknowledgements We wish to thank Anna Neubauer, Joscha Möller, Anne Albinus, and Anne Neumeister for help with data acquisition. We are grateful to the anonymous reviewers for their time and their helpful comments and suggestions. Funding for this research was provided by the European Union and the Free State of Saxony (SAB Grant 100098207).

\section{Appendix 1: Sources of the photographs used in Fig. 1}

The numbers in the bottom left corners were inserted for the study by the authors. Original image credits, from left to right:

1 Acer campestre 006 by Willow. Licensed under Creative Commons Attribution-Share Alike 2.5. Source: http://commons.wikimedia.org/wiki/File: Acer_campestre_006.jpg

34 Pedrengo cedro nel parco Frizzoni by Luigi Chiesa. Licensed under the Creative Commons AttributionShare Alike 3.0 Unported. Source: http://commons. wikimedia.org/wiki/File:Pedrengo_cedro_nel_parco_ Frizzoni.jpg.

10 Gleditsia triacanthos sunburst by Bostonian13. Licensed under Creative Commons Attribution-Share Alike 3.0. Source: http://commons.wikimedia.org/ wiki/File:Gleditsia_triacanthos_sunburst.jpg

52 Quercus phellos by Daderot. Licensed under Creative Commons CC0 1.0 Universal Public Domain Dedication. Source: http://commons.wikimedia.org/ wiki/File:Quercus_phellos_-_University_of_ Kentucky_Arboretum_-_DSC09357.JPG

4 Betula pendula 001 by Willow. Licensed under Creative Commons Attribution 2.5. Source: http:// commons.wikimedia.org/wiki/File:Betula_pendula_ 001.jpg

\section{Appendix 2: Preference ratings per species}

See Table 5. 
Table 5 Tree preference ratings, sorted by mean preference

\begin{tabular}{|c|c|c|c|}
\hline \multirow[t]{2}{*}{ Name } & \multicolumn{3}{|c|}{ Preference ratings } \\
\hline & Mean & Median & $\mathrm{SD}$ \\
\hline Gleditsia triacanthos & 77.2 & 81 & 16.8 \\
\hline Tilia cordata & 76.2 & 79 & 19.2 \\
\hline Carpinus betulus & 75.9 & 78 & 17.4 \\
\hline Acer campestre & 75.7 & 78 & 17.5 \\
\hline Liriodendron tulipifera & 75.0 & 78 & 19.2 \\
\hline Quercus robur L. ssp. robur Kl. et Kr. et Rol. & 74.7 & 78 & 20.3 \\
\hline Ulmus parvifolia & 74.1 & 77 & 20.9 \\
\hline Pyrus pyraster & 72.3 & 74 & 17.4 \\
\hline Magnolia acuminata & 72.1 & 74 & 17.5 \\
\hline Tilia platyphyllos & 70.5 & 73 & 19.8 \\
\hline Quercus rubra & 70.1 & 72 & 18.7 \\
\hline Robinia pseudoacacia & 69.5 & 73 & 22.8 \\
\hline Platanus occidentalis & 69.3 & 73 & 18.8 \\
\hline Platanus orientalis & 69.1 & 74 & 24.0 \\
\hline Carya illinoinensis & 68.8 & 73 & 21.6 \\
\hline Betula pendula & 67.8 & 71 & 23.8 \\
\hline Prunus avium & 67.6 & 70 & 19.6 \\
\hline Crataegus monogyna & 67.5 & 71 & 21.7 \\
\hline Prunus padus & 66.9 & 69 & 20.7 \\
\hline Sorbus aria & 66.5 & 69 & 20.4 \\
\hline Taxus baccata & 66.5 & 72 & 23.1 \\
\hline Quercus pubescens & 65.7 & 70 & 23.8 \\
\hline Alnus cordata & 65.3 & 67 & 19.6 \\
\hline Sorbus аисирагіa & 64.9 & 69 & 22.9 \\
\hline Populus alba & 64.0 & 68 & 22.0 \\
\hline Populus laurifolia & 63.7 & 68 & 20.9 \\
\hline Acer platanoides & 63.0 & 64 & 20.9 \\
\hline Alnus glutinosa & 62.8 & 66 & 22.9 \\
\hline Salix alba & 62.1 & 67 & 24.8 \\
\hline Celtis australis & 62.0 & 62 & 22.1 \\
\hline Malus sylvestris & 61.8 & 66 & 24.0 \\
\hline Magnolia stellata & 61.7 & 66 & 23.8 \\
\hline Quercus cerris & 60.9 & 63 & 21.5 \\
\hline Morus alba & 60.8 & 60 & 22.3 \\
\hline Betula utilis & 60.7 & 61 & 19.6 \\
\hline Fraxinus ornus & 60.6 & 61 & 20.8 \\
\hline Sorbus domestica & 60.5 & 62 & 22.6 \\
\hline Juglans regia & 60.4 & 63 & 22.4 \\
\hline Malus trilobata & 60.0 & 60 & 20.8 \\
\hline Malus tschonoskii & 59.9 & 61 & 21.4 \\
\hline Magnolia tripetala & 58.9 & 63 & 25.3 \\
\hline Cedrus deodara & 58.0 & 61 & 27.6 \\
\hline Cedrus atlantica & 56.6 & 59 & 30.7 \\
\hline Mespilus germanica & 56.2 & 58 & 24.3 \\
\hline Salix caprea & 54.8 & 55 & 24.0 \\
\hline Metasequoia glyptostroboides & 54.6 & 54 & 23.4 \\
\hline Magnolia macrophylla & 53.8 & 56 & 26.7 \\
\hline
\end{tabular}


Table 5 continued

\begin{tabular}{llrr}
\hline Name & Preference ratings & & \\
\cline { 2 - 4 } & Mean & Median & \\
\hline Quercus phellos & 53.7 & 55 & 24.1 \\
Pinus nigra & 52.2 & 55 & 30.5 \\
Pinus wallichiana & 51.0 & 48 & 25.8 \\
Cornus mas & 47.7 & 47 & 24.7 \\
Pinus bungeana & 46.2 & 44 & 21.7 \\
Pinus coulteri & 45.3 & 45 & 27.8 \\
Picea asperata & 45.3 & 43 & 26.6 \\
Pinus ponderosa & 44.6 & 40 & 25.8 \\
Pinus armandii & 41.9 & 34 & 23.2 \\
Cytisus scoparius & 40.2 & 35 & 28.7 \\
Juniperus virginiana & 38.8 & 32 & 28 \\
Picea omorika & 34.6 & 34.4 & 25.1 \\
Pinus aristata & & 25 \\
\hline
\end{tabular}

\section{References}

Akaike H (1987) Factor analysis and AIC. Psychometrika 52(3):317-332

Autorengruppe Bildungsberichterstattung (2014) Bildung in Deutschland 2014. Ein indikatorengestützter Bericht mit einer Analyse zur Bildung von Menschen mit Behinderungen, Bertelsmann Stiftung, Bielefeld

Balling JD, Falk JH (1982) Development of visual preference for natural environments. Environ Behav 14(1):5-28

Bates D, Mächler M, Bolker BM, Walker SC (2014) lme4: fitting linear mixed-effects models using lme4. ArXiv. http://arxiv.org/ abs/1406.5823

Belsley DA (1991) A guide to using the collinearity diagnostics. Comput Sci Econ Manag 4(1):33-50

Belsley DA, Kuh E, Welsch RE (1980) Regression diagnostics: identifying influential data and sources of collinearity. Wiley, New York

Berkowitz AR, Nilon CH, Hollweg KS (eds) (2003) Understanding urban ecosystems. Springer, New York

Berman MG, Jonides J, Kaplan S (2008) The cognitive benefits of interacting with nature. Psychol Sci 19(12):1207-1212

Bowler DE, Buyung-Ali LM, Knight TM, Pullin AS (2010) A systematic review of evidence for the added benefits to health of exposure to natural environments. BMC Public Health 10(1):456

Bréda NJJ (2003) Ground-based measurements of leaf area index: a review of methods, instruments and current controversies. J Exp Bot 54(392):2403-2417

Burns RM, Honkala BH (1990) Hardwoods. Agriculture handbook 654. No. 2 in Silvics of North America. U.S. Department of Agriculture, Forest Service, Washington, DC

Camacho-Cervantes M, Schondube JE, Castillo A, MacGregor-Fors I (2014) How do people perceive urban trees? Assessing likes and dislikes in relation to the trees of a city. Urban Ecosyst 17(3):761-773

Canty A, Ripley BD (2015) Boot: bootstrap R (S-plus) functions. R package version 1.1-9

Cekstere G, Nikodemus O, Osvalde A (2008) Toxic impact of the deicing material to street greenery in Riga, Latvia. Urban For Urban Green 7(3):207-217
Chen JM, Rich PM, Gower ST, Norman JM, Plummer S (1997) Leaf area index of boreal forests: theory, techniques, and measurements. J Geophys Res 102(D24):29,429

Conway TM (2007) Impervious surface as an indicator of $\mathrm{pH}$ and specific conductance in the urbanizing coastal zone of New Jersey, USA. J Environ Manag 85(2):308-316

Conway TM, Urbani L (2007) Variations in municipal urban forestry policies: a case study of Toronto, Canada. Urban For Urban Green 6(3):181-192

Davison AC, Hinkley DV (1997) Bootstrap methods and their applications. Cambridge University Press, Cambridge

Donovan GH, Butry DT, Michael YL, Prestemon JP, Liebhold AM, Gatziolis D, Mao MY (2013) The relationship between trees and human health. Am J Prev Med 44(2):139-145

Euostat (2013) Rural development statistics by urban-rural typology. Online resource, Eurostat. http://ec.europa.eu/eurostat/statisticsexplained/index.php/Rural_development_statistics_by_urbanrural_typology

Falk JH, Balling JD (2009) Evolutionary influence on human landscape preference. Environ Behav 42(4):479-493

Fraver S, D'Amato AW, Bradford JB, Jonsson BG, Jönsson M, Esseen PA (2013) Tree growth and competition in an old-growth Picea abies forest of boreal Sweden: influence of tree spatial patterning. J Veg Sci 25(2):374-385

Gerstenberg T, Hofmann M (2016) Perception and preference of trees: a psychological contribution to tree species selection in urban areas. Urban For Urban Green 15:103-111

Gillner S, Bräuning A, Roloff A (2014) Dendrochronological analysis of urban trees: climatic response and impact of drought on frequently used tree species. Trees 28(4):1079-1093

Gillner S, Vogt J, Tharang A, Dettmann S, Roloff A (2015) Role of street trees in mitigating effects of heat and drought at highly sealed urban sites. Landsc Urban Plan 143:33-42

Ginau A, Opp C, Sun Z, Halik Ü (2013) Influence of sediment, soil, and micro-relief conditions on vitality of Populus euphratica stands in the lower Tarim riparian ecosystem. Quat Int 311:146-154

Gundersen VS, Frivold LH (2008) Public preferences for forest structures: a review of quantitative surveys from Finland, Norway and Sweden. Urban For Urban Green 7(4):241-258 
Gómez-Baggethun E, Barton DN (2013) Classifying and valuing ecosystem services for urban planning. Ecol Econ 86:235-245

Hägerhäll CM, Ode Å, Tveit MS, Velarde MD, Colfer CJP, Sarjala T (2010) Forests, human health and well-being in light of climate change and urbanisation. In: Mery G, Katila P, Galloway G, Alfaro RI, Kanninen M, Lobovikov M, Varjo J (eds) Forests and society: responding to global drivers of change, IUFRO world series, chapter 12, vol 25. International Union of Forestry Research Organizations, Wien, pp 223-234

Haluza D, Schönbauer R, Cervinka R (2014) Green perspectives for public health: a narrative review on the physiological effects of experiencing outdoor nature. Int $\mathbf{J}$ Environ Res Public Health 11(5):5445-5461

Hartig T, Evans G, Jamner L, Davis D, Gärling T (2003) Tracking restoration in natural and urban field settings. J Environ Psychol 23(2):109-123

Hartig T, Mitchell R, de Vries S, Frumkin H (2014) Nature and health. Annu Rev Public Health 35(1):207-228

Hofmann M, Westermann JR, Kowarik I, van der Meer E (2012) Perceptions of parks and urban derelict land by landscape planners and residents. Urban For Urban Green 11(3):303-312

Honold J, Lakes T, Beyer R, van der Meer E (2015) Restoration in urban spaces: nature views from home, greenways, and public parks. Environ Behav 48(6):796-825

IPCC (2014) Climate change 2014. Synthesis report, United Nations Intergovernmental Panel on Climate Change, Genève

James P, Tzoulas K, Adams M, Barber A, Box J, Breuste J, Elmqvist T, Frith M, Gordon C, Greening K, Handley J, Haworth S, Kazmierczak A, Johnston M, Korpela K, Moretti M, Niemelä J, Pauleit S, Roe M, Sadler J, Thompson CW (2009) Towards an integrated understanding of green space in the European built environment. Urban For Urban Green 8(2):65-75

Jo HK, Ahn TW (2012) Landscape preferences for greenspace structures. J For Sci 28(1):56-62

Johnson A (1995) The good, the bad and the ugly: science, aesthetics and environmental assessment. Biodivers Conserv V 4(7): 758-766

Jucker T, Bouriaud O, Avacaritei D, Dănilă I, Duduman G, Valladares F, Coomes DA (2014) Competition for light and water play contrasting roles in driving diversity-productivity relationships in Iberian forests. J Ecol 102(5):1202-1213

Keniger L, Gaston K, Irvine K, Fuller R (2013) What are the benefits of interacting with nature? Int J Environ Res Public Health 10(3):913-935

Koffka K (1922) Perception: an introduction to the Gestalt-Theorie. Psychol Bull 19(10):531-585

Kuo FE, Sullivan WC (2001) Environment and crime in the inner city. Environ Behav 33(3):343-367

Lohr VI, Pearson-Mims CH (2006) Responses to scenes with spreading, rounded, and conical tree forms. Environ Behav 38(5):667-688

Maas J, Verheij RA, Groenewegen PP, de Vries S, Spreeuwenberg P (2006) Green space, urbanity, and health: how strong is the relation? J Epidemiol Community Health 60(7):587-592

Mitchell R, Popham F (2008) Effect of exposure to natural environment on health inequalities: an observational population study. Lancet 372(9650):1655-1660

Orians GH (2001) An evolutionary perspective on aesthetics. Bull Psychol Arts 2:25-29
R Core Team (2015) R: a language and environment for statistical computing. R Foundation for Statistical Computing, Wien

Radoglou K, Dobrowolska D, Spyroglou G, Nicolescu V (2009) A review on the ecology and silviculture of limes (Tilia cordata Mill., Tilia platyphyllos Scop. and Tilia tomentosa Moench.) in Europe. Die Bodenkult 60(3):9-19

Rambow R, Bromme R (1995) Implicit psychological concepts in architects' knowledge: how large is a large room? Learn Instr 5(4):337-355

Säumel I, Weber F, Kowarik I (2016) Toward livable and healthy urban streets: roadside vegetation provides ecosystem services where people live and move. Environ Sci Policy 62:24-33

Schroeder H, Flannigan J, Coles R (2006) Residents' attitudes toward street trees in the UK and US communities. Arboric Urban For 32(5):236-246

Sommer R (1997) Further cross-national studies of tree form preference. Ecol Psychol 9(2):153-160

Sommer R, Summit J (1995) An exploratory study of preferred tree form. Environ Behav 27(4):540-557

Sommer R, Summit J (1996) Cross-national rankings of tree shape. Ecol Psychol 8(4):327-341

Stamps AE III (2010) Use of static and dynamic media to simulate environments: a meta-analysis. Percept Mot Skills 111(2): 355-364

Statistisches Bundesamt (2015) Bildungsstand der Bevölkerung. Technical report, Statistisches Bundesamt, Wiesbaden

Summit J, Sommer R (1999) Further studies of preferred tree shapes. Environ Behav 31(4):550-576

Sæbø A, Borzan Ž, Ducatillion C, Hatzistathis A, Lagerström T, Supuka J, García-Valdecantos JL, Rego F, Van Slycken J (2005) The selection of plant materials for street trees, park trees and urban woodland. In: Konijnendijk C, Nilsson K, Randrup T, Schipperijn J (eds) Urban forests and trees. Springer, Heidelberg, pp 257-280

Thomsen P, Bühler O, Kristoffersen P (2016) Diversity of street tree populations in larger Danish municipalities. Urban For Urban Green 15:200-210

Tinio PPL, Leder H (2009) Natural scenes are indeed preferred, but image quality might have the last word. Psychol Aesthet Creativity Arts 3(1):52-56

Todorovic D (2008) Gestalt principles. Scholarpedia 3(12):5345

United Nations (2014) World urbanization prospects: the 2014 revision. United Nations, Department of Economic and Social Affairs, Population Division, New York

Vogt J, Gillner S, Hofmann M, Tharang A, Dettmann S, Gerstenberg T, Schmidt C, Gebauer H, van de Riet K, Berger U, Roloff A (2017) Citree: a database supporting tree selection for urban areas in temperate climate. Lands Urban Plan 157:14-25

von Döhren P, Haase D (2015) Ecosystem disservices research: a review of the state of the art with a focus on cities. Ecol Ind 52:490-497

Wertheimer M (1923) Untersuchungen zur Lehre von der Gestalt. II. Psychol Res 4(1):301-350

Zensusdatenbank (2013) Zensus 2011. Online resource, Statistische Ämter des Bundes und der Länder. http://ergebnisse.zensus2011. de/

Zheng B, Zhang Y, Chen J (2011) Preference to home landscape: wildness or neatness? Landsc Urban Plan 99(1):1-8 